\title{
Demonstration of motile treponemes in the aqueous humour in secondary syphilis
}

\author{
HENNING SCHMIDT AND E. GOLDSCHMIDT \\ Departments of Dermatology and Venereology and of Ophthalmology, Odense University Hospital, Denmark
}

As early as 1907 , only 2 years after the discovery of Spirochaeta pallida, Stephenson reported finding spirochaetes in the anterior chamber fluid in the eye of a 20-year-old woman who suffered from iridocyclitis complicating secondary syphilis.

Goldman and Girard (1967) reported two cases of congenital syphilis, both in women aged 52 years. The patients had interstitial keratitis and treponemes were found in the aqueous humour. Both patients had previously received treatment with arsenicals, bismuth, and iodides, after which the Wassermann reaction had become non-reactive. The authors stressed the value of anterior chamber paracentesis to diagnose the presence of active ocular syphilis.

Wells and Smith (1967) observed treponemes in the aqueous humour of a rabbit experimentally infected with syphilis. Smith and Israel (1968) reported a series of cases in which treponemes were found in the aqueous and certain other tissues in patients with late syphilis. The organisms were demonstrated by the use of specific fluoresceintagged antibody and were shown in a few instances to be virulent and pathogenic on passive transfer to other animals.

Smith, Israel, McCrary, and Harner (1968) inoculated the testis of a healthy rabbit with aqueous humour obtained at routine cataract extraction from a patient with a history of treated late syphilis; 1 month later it was possible to demonstrate the presence of spirochaetes in a testicular biopsy.

Smith $(1968,1969)$ reported the case of a 23-yearold woman who complained of blurred vision for 2 months. She was treated with topical and systemic steroids and atropine drops for a prolonged period. The VDRL test was non-reactive, and the FTA-ABS non-reactive to slightly reactive. Darkfield microscopy of the aqueous fluid revealed spirochaetes which were also found by fluorescent antibody staining.

Finally, MacFaul and Catterall (1971) demonstrated spiral organisms by fluorescent antibody

Received for publication March 16, 1972

Address: Odense University Hospital, DK 5000 Odense, Denmark staining in the aqueous humour of a homosexual male who had had secondary syphilis 6 months previously, complicated by iritis, for which he had been treated with penicillin.

Moore (1931) reported that severe and acute iridocyclitis was not uncommon in the early secondary stages of syphilis, when it was found in 4.6 per cent. of cases.

As there are few reports concerning the observation of spirochaetes in the eye in cases of untreated early syphilis we thought it justifiable to record the following case.

\section{Case history}

The patient, a married man aged 50 years, denied previous venereal disease. In October, 1971, he complained of pain on defaecation and noticed fresh blood in the stools. Cancer being suspected, he was transferred to a surgical ward and was operated upon for an ulcerative lesion near the anal sphincter. No serological tests for syphilis were performed. Histologically the rectal mucosa showed chronic and severe inflammation with lymphocytes and plasma cells but no signs of malignancy. The microscopic findings did not prompt further investigations.

In November the patient noticed a non-itching rash which did not last long. Later in the month an acute iritis affecting the right eye was diagnosed and treated with topical steroids and mydriatics. After a temporary improvement, the uveitis progressed, with severe ciliary injection, fibrinous exudates in the anterior chamber, and the development of posterior synechiae. Treatment with systemic steroids was started using $60 \mathrm{mg}$. prednisolone daily, and the patient was sent to the University Eye Clinic, where for the first time STS were performed. These were strongly positive and the TPI test reactive. The patient was therefore referred to the University Department of Dermatology and Venereology. Clinical examination revealed plantar papules and a few discrete penile papular lesions, in the serum from which spirochaetes were demonstrated by darkfield microscopy.

On the following day paracentesis of the anterior chamber of the right eye was performed under local anaesthesia. Motile spirochaetes were seen on darkfield microscopy of the aqueous humour, about three to six motile organisms per microscopic field. Treatment was 
commenced with procaine penicillin in oil and aluminium monostearate (PAM) 600,000 units daily for 10 days, after which the eye and skin lesions resolved.

Simultaneously, the dosage of steroids was tapered off. A febrile Herxheimer reaction did not occur after the first injection of penicillin, possibly because of the high dosage of steroids. On the 10th day the patient was discharged in good health with no objective signs in the eye or skin.

\section{Comment}

To our knowledge, spirochaetes have not been demonstrated in the aqueous humour in secondary syphilis in humans since the case recorded by Stephenson (1907).

Eye complications in syphilis may be of various kinds, but because of earlier effective treatment are now seldom seen. However, as many cases of syphilis are now transmitted by homosexual contact, the primary lesion may be overlooked and the diagnosis of syphilis first established in the secondary stage in which eye involvement may be manifest.

Consequently, STS should be performed routinely where the aetiology of an eye condition is not clear.

The patient was a married man who later admitted homosexual contacts. His anal primary lesion was not recognized as due to syphilis but was diagnosed as a 'simple ulcer' which, despite the suggestive histology, was not further investigated. Because of the long delay before the correct diagnosis was made and treatment started the man infected his wife who was found to have primary syphilis.

\section{Summary}

A case is reported of secondary syphilis with iritis in which darkfield examination of the aqueous humour revealed motile treponemes.

\section{References}

Goldman, J. N., and Girard, K. F. (1967) Arch. Ophthal. (Chicago), 78, 47

MacFaul, P. A., and Catterall, R. D. (1971) Brit. F. vener. Dis., 47, 159

MOORE, J. E. (1931) Amer. F. Ophthal., 14, 110

SMITH, J. LAWTON (1968) In 'Neuro-Ophthalmology', ed. J. L. Smith, vol. 4, p. 1. Mosby, St. Louis (1969) Surv. Ophthal., 14, 176

and Israel, C. W. (1968) Trans. Amer. Acad. Ophthal. Otolaryng., 72, 63

- - MCCRARY, J. A., and HaRner, R. E. (1968) Amer. F. Ophthal., 65, 242

STEPHENSON, S. (1907) Ophthalmoscope, 5, 142, 303

Wells, J. A., and Smith, J. Lawton (1967) In 'NeuroOphthalmology', ed. J. L. SMITH, vol. 3, p. 274. Mosby, St. Louis.

Mise en évidence de tréponèmes mobiles dans l'humeur aqueuse dans un cas de syphilis secondaire

SOMMAIRE

On rapporte un cas de syphilis secondaire avec iritis dans lequel l'examen au fond noir de l'humeur aqueuse a montré des tréponèmes mobiles. 